\title{
A Rare Case- Ileo-Ileal Intussusception with Acute Appendicitis
}

\author{
Raadhika Raja*, Sreeramulu PN, Srinivasan D, and Rahul Singh R \\ Department of Surgery, India
}

Received: April 25, 2018; Published: July 03, 2018

*Corresponding author: Raadhika Raja, Department of Surgery, Sri Devraj Urs Medical College, Tamaka, Kolar, India; Tel: +919036947250;

Email: drraadhikaraja@hotmail.com

\begin{abstract}
The occurrence of intussusceptions and appendicitis in the same patient has seldom been described in the paediatric population. We report a case of two-level ileo-ileal intussusceptions associated with acute appendicitis. A 2 years old boy had history of colicky abdominal pain, vomiting and non-passage of stools and flatus since 4 hours. On physical examination, he was irritable and restless. Abdominal ultrasound suggested ileocolicintussusceptions. Emergency laparotomy was performed and ileoilealintussusceptions was visualized. Ileoileal intussusceptions were reduced manually. After reduction, appendix was visualized and it was found to be inflamed. Appendicectomy was performed. Post-operative period was uneventful. We present this case because of its rarity in occurrence in a toddler in a rural setup as ours.
\end{abstract}

\section{Introduction}

Intussusceptions refer to a condition when one portion of the gut invaginates in to the lumen of the immediately adjacent segment of the bowel[1].The condition is encountered most commonly in paediatric population. Intussusception is most commonly an idiopathic condition and treated non-surgically by radiologic reduction.

The presence of acute appendicitis together with intussusceptions in children is very rare. Intussusceptions and appendicitis manifest similarly i.e., pain and tenderness in right lower quadrant of abdomen. Such a condition thus requires urgent attention and careful examination. If it is not detected in the early stages, severe complications like peritonitis and death may occur.

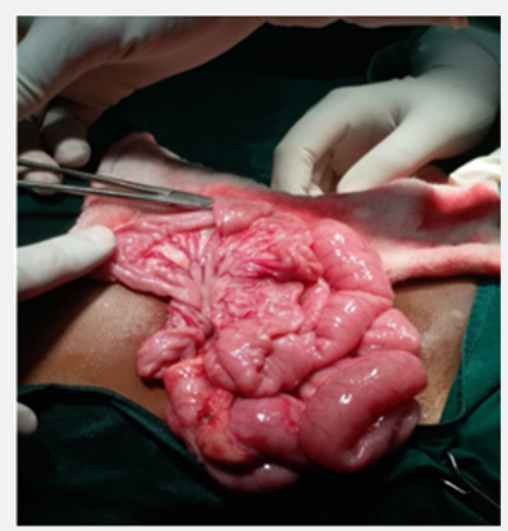

Figure 1: Intussusceptum and Intussuscipiens.
We report a case of ileoilealintussusceptions associated with acute appendicitis treated by manual reduction and appendectomy(Figure 1).

\section{Discussion}

Intussusception occurs when one segment of bowel telescopes into an immediately adjacent segment; almost invariably, proximal segment into the distal. It is believed that hyperplasia of Peyer's patches in the terminal ileum may be the initiating event.The condition is encountered most commonly in children, with a peak incidence between 5 and 10 months of age. Around $90 \%$ of cases are idiopathic. The incidence of intussusceptions with leading points in paediatric cases is approximately $2-12 \%$, with most common causes being Meckel's diverticulum and Henoch-Schönlein purpura. Other causes include lymphoma, duplication, haemangioma, and polyps of the intestine [2-4]. Intussusception is noted to be a major cause of intestinal obstruction in children.

Appendicitis on the other hand is a major surgical emergency in childhood. Appendicitis is the inflammation of the appendix most commonly due to obstruction of the lumen probably fecolith or lymphoid hyperplasia. The lifetime risk of developing appendicitis is $8.6 \%$ for males and $6.7 \%$ for females, with the highest incidence in the second and third decades(Figure 2).

The peak incidence of the two conditions shows wide variation. Therefore, it is important to consider the possibility that both conditions may co-exist while making a diagnosis. 
Intussusception is a major cause of intestinal obstruction in children. The most common type of intussusception reported being ileo-colic $(77 \%)$ whereas ileo-ileal has been reported only in $5 \%$ of cases. In general, we do not investigate for the leading points as most cases of ileo-colic intussusception in children are not associated with a leading point. In our case, had we not examined for the presence of an associated disease, we would have only performed a simple reduction and missed the diagnosis of appendicitis. Hence, it is necessary to investigate for associated diseases when a patient is diagnosed to have intussusception.

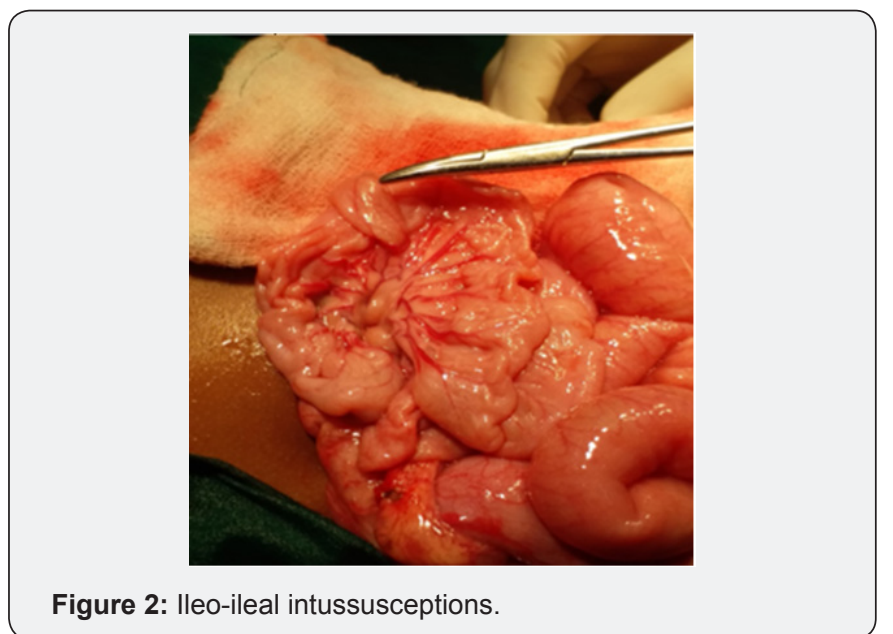

Intussusception with appendicitis, such as in the case reported here is very rare in both paediatric patients and adults. Few cases have been reported since those described by Bevan[5] in 1957. Kang et al.[6] reported a cecocolic intussusception caused by appendicitis in a 73-year-old woman, which was diagnosed by abdominal and pelvic CT, and subjected to surgery. The intussusception resolved without manual reduction(Figure 3).

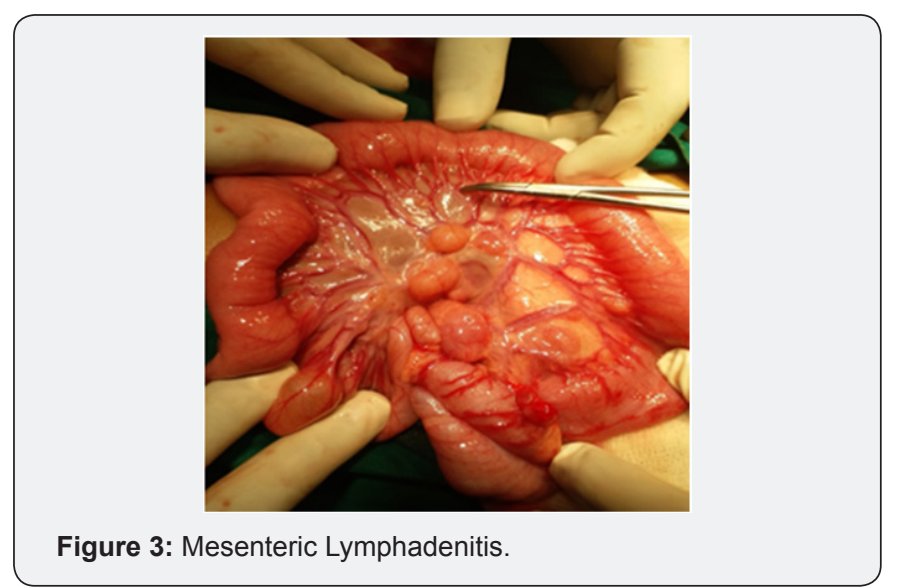

In our case, we did not find any luminal obstruction of the appendix. The causal relationship was not clear. We may consider that the appendicitis was triggered by intestinal obstruction owing to intussusception. Additional investigation is necessary to determine a causal relationship. Current trends in management of appendicitis have greatly improved. Appendicitis has generally been considered relatively easy to diagnose though numerous other diseases mimic appendicitis. Thus, it is very important to always determine the cause and presence of any associated diseases as both are common diseases of paediatric population.

We would like to conclude that it is essential to rule out other pathologic conditions of intestines such as polyps, adenoma, submucosal lipoma and appendicitis in cases of intussusception.

\section{Conclusion}

As it is rightly said-Abdomen is the playground of a surgeon, every attempt has hidden surprises to look for. In our patient little did we know that a 2-year-old boy with RIF pain will have so much pathology going on inside- Intussusception Appendicitis(Figure 4).Whenever in doubt, always open and see. We were lucky enough to look for leading points that has helped give the child a healthier and bright future.

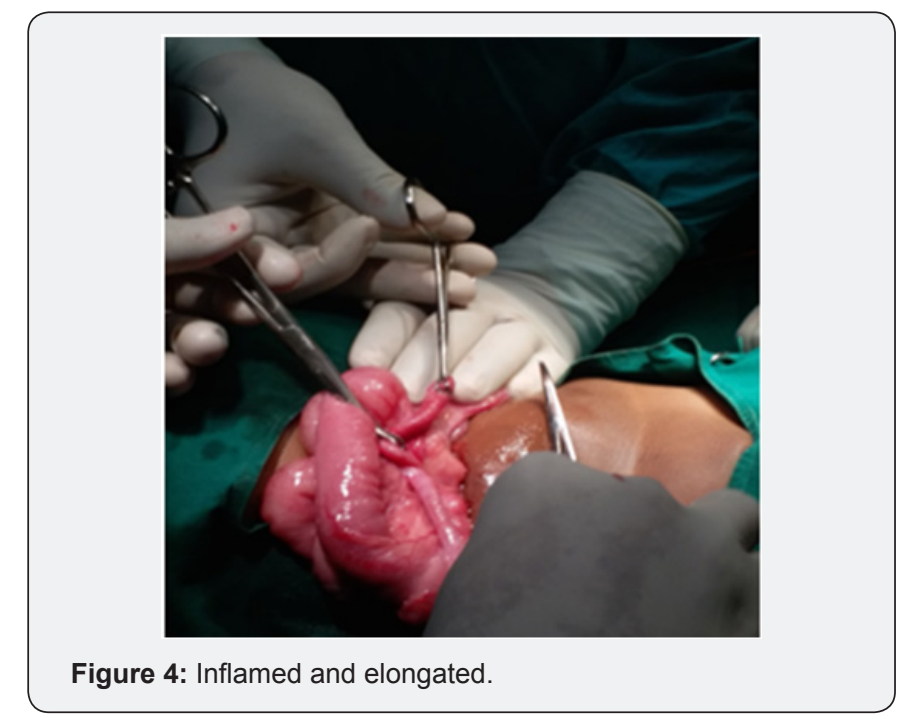

\section{References}

1. Shelton T, McKinley R, Schwartz RW (2003) Acute appendicitis: current diagnosis and treatment. Current surgery60(5):502-505.

2. Ksia A, Mosbahi S, Brahim MB, Sahnoun L, Haggui B, et al (2013) Recurrent intussusception in children and infants. Afr J PaediatrSurg10(4):299-301.

3. Mills RW, McCrudden K, Gupta VK, Britton A, Al Qahtani M, et al. (2011) Intussusception caused by heterotopic pancreatic tissue in a child. Fetal and paediatric pathology 30(2):106-110.

4. Sonmez K, Turkyilmaz Z, Demirogullari B, Karabulut R, Kale N, et al (2012) Intussusception in children: Experience with 105 patients in a department of paediatric surgery, Turkey. S Afr J Surg50(2):37-39.

5. Das P, Jones D (2014) Chromosomal microarray testing in children: Experience from a New Zealand secondary care hospital. J Paediatr Child Health 50(7):574-575.

6. Kang J, Lee KY, Sohn SK (2014)Cecocolic intussusception in adult caused by acute appendicitis. Case reports in surgery 2014: 3 . 


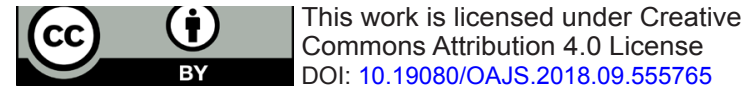

- Quality Editorial service

- Swift Peer Review

- Reprints availability

- E-prints Service

- Manuscript Podcast for convenient understanding

- Global attainment for your research

- Manuscript accessibility in different formats

( Pdf, E-pub, Full Text, Audio)

- Unceasing customer service

Track the below URL for one-step submission https://juniperpublishers.com/online-submission.php 